MEMÓRIA

\title{
Instituto Biológico de São Paulo
}

\author{
APRESENTAÇÃO \\ Maria Alice Rosa Ribeiro*
}

\section{Um breve e intenso começo}

O Instituto Biológico - IB nasceu de uma praga: a broca cafeeira. Para que o leitor forme melhor juízo do que foi dito, nasceu dos exitosos resultados obtidos pela Comissão para Estudo e Debelação da Praga Cafeeira no combate à broca. Origem semelhante também ocorrera com o Instituto Sorotherápico Butantan, que teve como estopim a peste bubônica, que grassava em Santos em 1899, e a falta de soro antipestoso para atender aos doentes. De situações negativas e trágicas - uma, para a vida humana, outra, para a vida econômica - resultaram instituições duradouras que, ao longo de suas trajetórias, cumpriram seus propósitos, instituíram novos, se adaptaram às transformações sociais e econômicas e trouxeram contribuições significativas para as sociedades paulista e brasileira. Ambas nelas permanecem ainda hoje.

Desde 1913, sinais de algum problema nas lavouras cafeeiras de Campinas eram perceptíveis, mas, como se tratava de uma das regiões mais antigas desse cul-

* Professora adjunta de Economia da FCL/Unesp (aposentada) e pesquisadora colaboradora do Centro de Memória da Unicamp - CMU. Nesta Memória, quero prestar um tributo a meu tio Jorge Uchoa Ralston, um dos primeiros citricultores de Bebedouro, quem primeiro me falou das doenças das laranjeiras e da Dra. Victória Rossetti. 
tivo, o problema ficou mascarado. A baixa produtividade dos cafeeiros poderia ser resultado do envelhecimento da planta.

Dez anos depois, o problema localizado adquiriu extensão e os sinais tornaram-se manifestaçóes generalizadas de que havia uma doença ou uma praga na cultura cafeeira. Em 1924, o secretário da Agricultura, Comércio e Obras Públicas do Estado de São Paulo, Gabriel Ribeiro dos Santos, foi informado por um fazendeiro de Campinas de que sua produção e a de seus vizinhos estavam sendo atacadas por uma praga desconhecida. Em visita à região, o diretor de Agricultura, Adalberto de Queiroz Teles, e o naturalista e entomologista do Museu Paulista, Adolph Hempel, examinaram os cafezais de quatro das maiores fazendas de Campinas (Chácara da Barra, Bom Retiro, Mato Dentro e Lapa) e concluíram tratar-se de uma praga terrível e perigosa para a lavoura paulista. Na fazenda Mato Dentro, ${ }^{1}$ a situação era crítica - um colono encheu um saco com café em coco, correspondente à sua colheita habitual de um talhão. Em vez de pesar os costumeiros 45 quilos, o saco pesou 16. O inseto, conhecido popularmente por broca, perfurava a coroa do grão e, no seu interior, se reproduzia, sendo que a polpa servia de alimento para suas larvas e ninfas. A situação levou o secretário da Agricultura a solicitar a colaboração do Ministério da Agricultura, que enviou a Campinas Arthur Neiva, do Instituto Oswaldo Cruz-Manguinhos, e Ângelo da Costa Lima, do Ministério da Agricultura, para realizarem a identificação da praga. Tratava-se do Hypothenemus hampei (FERR, 1867), o mesmo inseto que atacava as plantações de Java e da Sumatra, sendo confirmado por dois entomologistas de renome internacional.

Após a identificação, formou-se a Comissão de Estudos e Debelação da Praga Cafeeira, composta inicialmente por Arthur Neiva, Ângelo da Costa Lima e Edmundo Navarro de Andrade² e subordinada à Secretaria da Agricultura, Comércio e Obras Públicas do Estado de São Paulo, ficando encarregada de mapear a extensão da praga, estudar a biologia do inseto e propor medidas para seu controle e extinção.

Ao final de três anos, a praga havia sido controlada, porém, erradicá-la era considerado impossível pela própria comissão. A campanha contra a broca conseguiu

1 A Fazenda Mato Dentro era de propriedade da Viscondessa de Campinas, Maria Luiza de Souza Aranha, tendo recebido como herança da sesmaria e engenho de seu pai. Foi a primeira fazenda campineira a introduzir o café por volta de 1840. Na época da praga, não mais pertencia à família Souza Aranha. Hoje, é de propriedade do Estado de São Paulo e nela funcionam o Centro Experimental do Instituto Biológico e o Parque Ecológico Monsenhor Emilio José Salim, ou Parque Ecológico de Campinas.

2 Arthur Neiva era pesquisador do Instituto Oswaldo Cruz-Manguinhos e foi diretor do Serviço Sanitário do Estado de São Paulo, entre 1916 e 1920 (RIBEIRO, 1993). Costa Lima era professor da Escola de Agronomia do Rio de Janeiro e trabalhou em entomologia agrícola no Instituto Biológico da Defesa Agrícola do Ministério da Agricultura e Navarro de Andrade era diretor do Horto Florestal da Cantareira, tendo-se notabilizado pela introdução de eucalipto no país (RIBEIRO, 1997). 
controlar seu avanço em muitas das 3.000 propriedades atingidas, mas apenas nas pequenas foi eliminada completamente.

No seu relatório final, Neiva (1928) lançava a ideia da formação de um centro de pesquisas voltado para a defesa da agricultura. Argumentava que o empirismo, os métodos de tentativa e erro, realizados às cegas, a destruição simples pelo fogo e as benzeduras eram coisas do passado. Para desenvolver-se, a agricultura paulista deveria apoiar-se em alicerces científicos; a broca mostrara o caminho e dera o exemplo de que é possível controlar ou retardar o ritmo de propagação de pragas e doenças com base na ciência. Para atender a objetivos mais abrangentes, além da cultura cafeeira, era necessário fundar uma instituição permanente que cuidasse das condições de sanidade das diversas culturas, da criação de animais de interesse econômico e da saúde dos trabalhadores do campo.

Graças à atuação da comissão e ao trabalho de convencimento promovido por Neiva, no âmbito da política estadual, junto ao secretário de Estado de Negócios da Agricultura, Indústria e Comércio, Fernando de Souza Costa, e ao governador Julio Prestes, no final das atividades da Comissão de Estudo e Debelação da Praga Cafeeira, nascia o Instituto Biológico de Defesa Agrícola e Animal, em 26 de dezembro de 1927.

\section{0 Instituto Biológico: organização e pessoal}

A criação do Instituto Biológico foi incorporada à reforma da Secretaria da Agricultura, promovida durante a gestão de Fernando Costa, em 1927. ${ }^{3}$ Com ela, completava-se a estrutura de institutos públicos de pesquisa agropecuária. Ao lado do Instituto Agronômico de Campinas - IAC, destinado à pesquisa do fomento agrícola, à seleção de cultivares, à correção do solo para as diversas culturas, etc., criou-se o IB, destinado à pesquisa de sanidade vegetal e animal e à defesa agropecuária.

A atividade agrícola é distinta de outras atividades econômicas, porque lida com seres vivos, animais e plantas, e não com coisas inanimadas. A preservação e a defesa da vida são o requisito fundamental para a elevação da qualidade e da produtividade. Disso resulta ser fundamental a incorporação da ciência biológica, num sentido amplo, à atividade agrícola, o que lhe confere especificidade em relação aos outros setores produtivos.

3 A reforma de 1927 mudou o nome da Secretaria da Agricultura, Comércio e Obras Públicas para Secretaria de Estado de Negócios da Agricultura, Indústria e Comércio. Em 1946, com nova reforma, o nome passou a ser Secretaria da Agricultura e, finalmente em 1979, Secretaria de Agricultura e Abastecimento, como se mantém até hoje (MARTINS, 1991). 
Inúmeras atividades compunham a defesa agropecuária, tais como estudar a sanidade animal e vegetal, analisar as substâncias empregadas contra doenças e pragas fungicidas, inseticidas, parasiticidas, etc., orientar os lavradores e criadores no combate às epifitias e epizootias e organizar a campanha contra formigas, cupins e pragas da lavoura. Além de preparar e produzir soros, vacinas e produtos terapêuticos para o tratamento e a profilaxia das doenças dos animais, são atividades do IB divulgar seus estudos por meio de publicaçōes próprias, estabelecer intercâmbio com os centros agrícolas nacionais e internacionais e organizar cursos práticos sobre os estudos e as pesquisas desenvolvidas (Lei n. 2.243, de 26 de dezembro de 1927).

O primeiro diretor superintendente do IB foi o próprio Arthur Neiva, que, com jurisdição em todo o estado, era o responsável por imprimir a orientação científica e prática à instituição, auxiliado por dois superintendentes, um encarregado da Divisão de Defesa Animal e outro, da Divisão de Defesa Vegetal. Ficava o Instituto Biológico formado por essas duas grandes divisões: Animal e Vegetal. À Divisão Vegetal estavam ligadas as Seçôes de Botânica e Agronomia, Química, Entomologia e Parasitologia Agrícolas e Fitopatologia; à Divisão Animal, as de Fisiologia, Bacteriologia, Entomologia e Parasitologia Animal e Anatomia Patológica. Subordinadas diretamente à diretoria, encontravam-se a Biblioteca, a Seção de Desenho e de Fotomicroscopia, a Administração e, por fim, a Contabilidade. Passavam a fazer parte da instituição recém-criada a Seção de Botânica e a Estação Biológica do Museu Paulista. No regulamento, ficavam estabelecidos dois postos de expurgo do café com câmara de bissulfureto de carbono, um na capital e outro em Santos, para a manutenção do combate à broca (Decreto n. 4.394, de 21 de março de 1928).

Essa foi a primeira estrutura organizacional do IB, alterada e adaptada às novas questôes postas pelo desenvolvimento da agricultura paulista e pela organização da própria Secretaria da Agricultura. Em que pesem as alteraçóes, ao longo de seus 84 anos, a missão central da instituição manteve-se. Hoje, lê-se no seu site: A MISSÃO do IB é " $[\ldots]$ gerar e transferir conhecimento científico e tecnológico para o agronegócio nas áreas de sanidade animal e vegetal, visando a melhoria da qualidade de vida da população e a preservação do meio ambiente" ${ }^{4}$ Mudou a terminologia - agropecuária para agronegócio. Incorporaram-se novas questôes ligadas ao meio ambiente, mas a instituição continuou a desvendar, pela ciência, pela pesquisa e pela experimentação, no laboratório e no campo, as doenças e as pragas que afligiam os produtores rurais nas mais variadas culturas e criaçōes, a evitar desastres no meio

4 Disponível em: <http://www.biológico.sp.gov.br>. Acesso em: 23 fev. 2010. 
ambiente e na saúde dos trabalhadores do campo e a proteger a saúde da população, cuidando da segurança dos alimentos comercializados.

Uma instituição reflete as concepçôes, os projetos e as atividades do dia-a-dia dos seus dirigentes, pesquisadores e técnicos, que lhe dedicam parte significativa de suas vidas profissionais. É claro que há condicionantes externos que limitam a vida da organização, nela interferindo, às vezes, de forma decisiva. ${ }^{5}$ Assim foi e é no IB. Desde seu começo, contou com dirigentes, pesquisadores com formação acadêmica e científica da maior grandeza. E isso se deveu a Arthur Neiva, que soube recrutar profissionais com sólida formação científica para dirigirem as duas grandes divisões - Sanidade Animal e Vegetal. Para a de Sanidade Animal, Neiva convidou um cientista de renome internacional, Henrique da Rocha Lima (18791956), seu ex-colega do Instituto Manguinhos. Médico, formado na Faculdade de Medicina do Rio de Janeiro, vinha ele do Instituto de Moléstias Tropicais de Hamburgo, Alemanha, onde trabalhou em pesquisas no campo da anatomia patológica e da microbiologia, entre 1910 e $1928 .^{6}$ Notabilizou-se pela descoberta do agente causador do tifo exantemático e pela identificação da lesão característica da febre amarela, "sinal Rocha Lima", que possibilitou o diagnóstico preciso e a realização de novos estudos da moléstia. Além do Instituto de Moléstias Tropicais, outra influência trazida por Rocha Lima na organização e concepção do IB veio de Manguinhos, da Escola de Oswaldo Cruz, que exerceu papel de paradigma de instituição científica e de onde eram egressos não somente Arthur Neiva e Rocha Lima, mas também o grupo de jovens cientistas recrutados por eles. Pesquisadores e ex-estudantes dos núcleos científicos do Rio de Janeiro - Manguinhos e a Escola

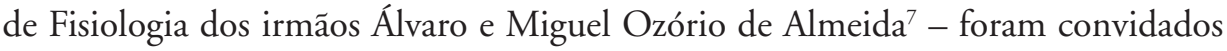
a ingressar na nova instituição.

5 Subordinado ao governo do Estado de São Paulo, o IB sempre enfrentou as políticas dos governos ora favoráveis, como foi o período até 1949, ora desfavoráveis. Em 1953, Agesilau A. Bitancourt, diretor do IB, foi obrigado a pedir demissão por discordar do secretário estadual da Agricultura. Nos anos 1980 e 1990, o IB foi, por diversas vezes, ameaçado de privatização, venda do seu patrimônio e mudança para o regime administrativo-institucional - Organização Social.

6 O Instituto de Moléstias Tropicais de Hamburgo era um órgão científico, voltado para o estudo e a pesquisa de doenças tropicais, organizado pelo governo alemão para defesa sanitária de suas colônias tropicais. Inteiramente destruído pelas duas guerras, continuou seu trabalho mesmo depois de a Alemanha perder todas as suas colônias, pois se tornara o centro de referência internacional para todos os estudiosos de moléstias tropicais (RIBEIRO, 1997, p. 52).

7 A divisão animal contou, no seu começo, com médicos e veterinários formados pela Faculdade de Medicina e da Medicina Veterinária do Rio de Janeiro e alunos dos cursos de especialização, em Manguinhos, e dos irmãos Ozório de Almeida. Entre os primeiros, estavam Genésio Pacheco, Paulo Enéas de Galvão, Celso Rodrigues, Adolfo Martins Penha, Otto Bier, José Reis, etc. Apenas dois estudantes eram da Faculdade de Medicina de São Paulo, que ingressaram como estagiários e, depois de formados, tornaram-se pesquisadores de carreira: Paulo da Cunha Nóbrega e Zeferino Vaz. 
Coube ao chefe da Divisão Animal, Henrique da Rocha Lima, a tarefa de consolidar e imprimir especificidade à instituição de defesa sanitária da produção agrícola de São Paulo. ${ }^{8} \mathrm{O}$ eixo central consolidou-se em torno das investigaçôes científicas das patologias dos seres vivos, vegetais e animais. Uma combinação especial sustentava a concepção do instituto - ciência básica e aplicada - e um entrosamento inovador entre cientistas especializados em biologia vegetal e outros dedicados à biologia animal. Na opinião de Rocha Lima, ambos constituíam uma fecunda associação, muito rara em outros países, e dela se esperavam os melhores resultados para o desenvolvimento da ciência.

O recrutamento de pesquisadores para a Divisão de Sanidade Vegetal foi totalmente distinto do da Divisão de Sanidade Animal. Como o embrião do IB havia sido a Comissão de Estudo e Debelação da Praga Cafeeira, os pesquisadores que trabalhavam na comissão foram convidados a ingressar no novo instituto. ${ }^{9} \mathrm{De}$ início, ocupou a superintendência da Divisão Vegetal o diretor da Agricultura da Secretaria de Estado de Negócios da Agricultura, Indústria e Comércio, Adalberto de Queiroz Teles, ${ }^{10}$ que participara da comissão da broca. Entretanto, em 1931, foi substituído pelo engenheiro agrônomo Agesilau Antonio Bitancourt (1899-1987). A Divisão Vegetal somente encontrou orientação segura e certa com Bitancourt. Nos primeiros dois anos de funcionamento do IB, essa divisão e suas seçôes dedicaram-se quase que exclusivamente a dar continuidade ao controle biológico da broca, por meio do predador natural, a vespinha de Uganda, trazida da África e reproduzida nos laboratórios do IB, para ser distribuída aos cafeicultores.

Na verdade, o que Bitancourt realizou na Divisão de Sanidade Vegetal correspondeu ao que Rocha Lima fizera na Divisão Animal: introduziu a moderna fitopatologia e orientou novas pesquisas para identificação das doenças das plantas e para estudo da biologia das bactérias, dos vírus e dos fungos causadores das patologias, bem como para a formulação de medidas de controle, prevenção e extinção. Em 1931, quando contratado, já era conhecido por seus trabalhos no campo da fitopatologia. Nascido em Manaus, em 1899, era engenheiro agrônomo formado pelo Institut National Agronomique de France, licenciado e doutor em Ciências pela Sorbonne.

8 Em 1933, Neiva afastou-se da direção do IB para ser interventor federal na Bahia, seu estado natal. A gestão de Rocha Lima marcou o período de consolidação e reconhecimento internacional da instituição, a idade de ouro. Aposentou-se em 1949, com 70 anos.

9 Faziam parte da comissão e migraram para o IB Adolpho Hempel, entomologista e naturalista do Museu Paulista; José Pinto da Fonseca, entomologista e naturalista viajante do mesmo museu; Mario Autuori, Alberto Federman, fotógrafo científico, e Frei Thomaz Borgmeier, entomologista do Museu Nacional, convidado por Neiva.

10 Adalberto de Queiroz Teles substituiu Ângelo da Costa Lima na comissão. 
De volta ao Brasil, ingressou como fitopatologista assistente no Instituto Biológico de Defesa Agrícola do Ministério da Agricultura e, mais tarde, foi diretor da Estação Experimental de Agrostologia do Ministério da Agricultura, no Rio de Janeiro. De 1926 a 1929, lecionou Botânica, Fitopatologia e Microbiologia Agrícola na Escola Superior de Agronomia Luiz de Queiroz - Esalq, em Piracicaba ${ }^{11}$.

Por essa breve nota biográfica dos dois personagens, já se percebe o espírito de verdadeira instituição de pesquisa de caráter universitário que se formou no IB, reunindo profissionais das variadas formações: médicos, veterinários, naturalistas, entomologistas, fitopatologistas, engenheiros agrônomos, químicos, etc., com o propósito de conhecer as doenças e as pragas que acometiam as lavouras e as criaçóes. De fato, o IB foi um marco na vida cultural e científica da cidade de São Paulo. Somente com sua fundação formou-se um núcleo científico na capital do Estado, voltado para as ciências e a moderna tecnologia que se faziam nos grandes centros da Europa e dos Estados Unidos.

\section{Instituto Biológico: pesquisa e impacto na agropecuária - aves e citros}

Para esta Memória do IB, escolhi dois temas de pesquisa, influenciados pelos cientistas Rocha Lima e Bitancourt - a avicultura e a citricultura. Seu programa de estudos foi gestado nos anos 1930, mas, ainda hoje, permanece e repercute no avanço das ciências, na defesa sanitária e no desenvolvimento da economia agrícola paulista e brasileira.

Sob pena de ser injusta com a memória da instituição, pois o IB é um manancial de pesquisas e estudos inovadores, escolhi dois documentos históricos de grande importância e que marcaram de forma indelével o caráter da instituição: um de sanidade animal; e outro, de vegetal. $\mathrm{O}$ primeiro data dos começos de uma linha de pesquisa pioneira - o estudo das doenças das aves de interesse econômico. No artigo/documento, o pesquisador José Reis narra sua excursão à Colônia Evangelista de Palma, localizada nas proximidades de Quatá, na Alta Sorocabana, próximo à fronteira com o Paraná. A narrativa fornece uma ideia da diversificação da ocupação do solo paulista e da atividade econômica, da ambientação criada por imigrantes letôes e japoneses. E mais, fornece a exata noção do entrosamento entre

11 Por indicação do interventor Armando Salles de Oliveira, Bitancourt participou da comissão organizadora da Universidade de São Paulo, em 1933. Bitancourt foi diretor do IB após a aposentadoria de Rocha Lima, em 1949, até 1953. 
as diversas seções científicas e técnicas do Instituto para atender às dificuldades dos agricultores, e da sua função educativa, ao difundirem conhecimentos técnicos e científicos e promoverem a aproximação dos homens do laboratório com os homens do campo e a troca de experiências.

$\mathrm{O}$ outro artigo/documento marca um evento, uma descoberta, um acontecimento da maior relevância, um resultado de anos de investigação sobre as doenças dos citros. Trata-se do primeiro artigo publicado pela pesquisadora Victoria Rossetti, no qual descreve a doença dos citros, popularmente conhecida por "amarelinho", e por ela batizada de Clorose Variegada dos Citros, CVC, e por seus parceiros e coautores, Joseph Marie Bove e Monique Garnier, do Institut National de la Recherche Agronomique - Inra, que revelam a descoberta da bactéria Xilella fastidiosa como agente causal da doença.

\subsection{Um pouco da história dos estudos das doenças das aves de importância econômica}

A escolha do tema patologias das aves para marcar a memória do IB deve-se à importância da avicultura na economia brasileira, quer como atividade de pequenos e médios criadores, quer como de grandes granjas de corte e de postura. O Brasil tem a terceira maior produção de carne de frango do mundo ${ }^{12}$ e ocupa a primeira posição na exportação mundial. Em parte, o IB contribuiu para a conquista dessa posição, ao lançar as bases da pesquisa sobre patologias aviárias, ao identificar pela primeira vez e controlar doenças como a Newcastle e a Gumboro, ao estabelecer técnicas de diagnósticos de doenças e ao realizar os primeiros estudos de aviários em grande escala.

A ideia de estudar as doenças das aves de consumo doméstico foi sugerida a José Reis por Rodolpho von Ihering (1889-1939), ${ }^{13}$ que, em suas viagens, observara, com frequência, o desespero dos pequenos criadores de galinhas com a perda da criação, em virtude de algum surto epidêmico. Em 1931, Rocha Lima estimulou o funcionamento de um setor de patologia aviária, coordenado por Reis. Com o

12 Maiores produtores de carne de frango em toneladas: EUA, com 16,1 milhões; China, com 10,3 milhões e Brasil, com 9,3 milhões, segundo dados para 2008 (RUBIN; OLIVEIRA; SILVA, 2009).

13 Zoólogo, trabalhou como assistente na Seção de Entomologia e Parasitologia Animal, e mais tarde foi chefe da Seção de Zoologia. Dedicou-se ao estudo das piracemas da região do Estado de São Paulo, na represa Billing, nos rios Mogi-Guaçu (em Cachoeira de Emas), Tietê (em Salto do Itu) e Piracicaba (em Salto de Piracicaba). A partir de 1931, dedicou-se exclusivamente aos trabalhos de bioeconomia, na área da piscicultura. Disponível em: <http:// pt.wikipedia.org/wiki/Rodolpho_von_lhering>. Accesso em: 2 abr. 2011. 
crescente volume de trabalho, o setor foi transformado em seção denominada pelo estranho nome de Ornitopatologia, que passou a contar com mais um pesquisador, Paulo da Cunha Nóbrega, ${ }^{14}$ além de Reis e Anita Swensson. Durante seis anos, os três pesquisadores investigaram um amplo espectro de patologias aviárias em pequenas e médias criações, totalizando 70 mil aves. Assim, reuniram-se conhecimentos que nenhuma instituição de sanidade animal jamais havia obtido. Sobre esse período, José Reis (1983) disse: "Para conseguir um trabalho mais ou menos eficiente em relação às doenças de aves, eu tive de passar uns 6 anos sem pensar noutra coisa, atolado em galinha até as orelhas".

O pioneirismo das investigações foi concretizado na publicação do livro Doença das aves. Tratado de Ornitopalogia, de 1936 - um marco histórico na produção do conhecimento na área. Foi reconhecido pelo professor F. R. Beaudette, da Universidade de Rutgers, New Jersey, que o adotou como bibliografia obrigatória do seu curso no mesmo ano da publicação. Se, nos Estados Unidos, o livro veio a preencher uma lacuna no conhecimento das patologias aviárias, imagine-se no Brasil, onde se ressentia da falta de qualquer estudo sistemático e de caráter científico. $\mathrm{O}$ conhecimento gerado permitiu que se desenvolvesse tecnologia na produção de vacinas e de outras substâncias medicamentosas.

Em 1945, o IB preparava uma variedade de produtos destinados exclusivamente ao combate de doenças das aves: o antígeno colorido para combate à pulorose, quatro tipos de vacinas preventivas contra bouba, difteria, espiroquetose, tifo aviário, soro preventivo contra a cólera das galinhas, o bacteriófago preventivo contra o tifo aviário, três tipos de preparados curativos contra a difteria, a coriza e o gogo das galinhas, um preparado contra os piolhos das aves, dois tipos de vermífugos e um purgativo.

A criação em maior escala de animais confinados acarreta a necessidade de maiores cuidados com a higiene e as condiçóes sanitárias, e o grande desafio da seção foi a instalação de um imenso aviário, destinado a fornecer ovos e carne para os operários e os funcionários da fábrica de motores de aviōes, Fábrica Nacional de Motores, FNM, pertencente ao Ministério da Aeronáutica, na Baixada Fluminense. Em pouco mais de um ano, Paulo da Cunha Nóbrega e outros técnicos da seção montaram uma criação modelar de 9 mil aves, com 5 mil poedeiras, que forneciam 250 dúzias de ovos diariamente. Com a experiência pioneira de construção do aviátituto Bacteriológico de Hamburgo, sob a supervisão do Prof. Zeissler, completando seu estágio no Instituto Robert Koch e na Universidade de Berlim, entre 1938 e 1939. Sucedeu a José Reis na chefia da Seção de Ornitopatologia, em 1942, e foi diretor do IB entre 1954-1967 e 1969-1971. 
rio, preparou-se o terreno para a transformação da avicultura em uma atividade capaz de se organizar com economias de escala e sem temer as frequentes epizootias.

A continuidade dos estudos sobre doenças das aves e a responsabilidade pelo diagnóstico de patologias, com o emprego das mais modernas técnicas, prosseguem, hoje, no Centro Avançado de Pesquisa Tecnológica do Agronegócio Avícola de Descalvado e de Bastos. As unidades localizam-se na região com maior concentração de criadores de aves, prestam atendimento ao município, que é o maior produtor de ovos do país, com 7,5 milhōes de unidades/dia, correspondendo a $25 \%$ da produção do Estado de São Paulo e a 14\% da brasileira, recorde de postura - 144 ovos por segundo (RIBEIRO, 2010, p. 107).

\subsection{Um pouco da história dos estudos das doenças e da Clorose Variegada dos Citros (CVC)}

A escolha de documento que marca a descoberta de uma doença dos citros, em primeiro lugar, atende a um antigo desejo de homenagear a Dra. Victoria Rossetti, ${ }^{15}$ por ser mulher, uma grande cientista e ter se dedicado à carreira de pesquisadora em uma instituição pública, deixando um imenso legado de contribuições à pesquisa científica e tecnológica do país, em especial à citricultura. Em segundo lugar, é um exemplo de como se faz a "boa ciência", entendida como aquela que visa solucionar problemas que afligem os produtores, realiza pesquisa laboratorial e de campo, de acordo com postulados da ciência, e articula uma rede de instituiçóes de pesquisa públicas e privadas e empresas privadas para promover o melhor, o mais rápido e seguro resultado. E, por fim, em terceiro lugar, pela importância econômica da citricultura para o Brasil, que é o maior produtor e exportador mundial de suco de laranja concentrado e congelado (SLCC), e para São Paulo, responsável por mais de $80 \%$ da produção e da exportação.

A vinda de Agesilau A. Bitancourt para o IB marcou o início da pesquisa de citros na Seção de Fitopatologia e Entomologia, em 1931. Por meio dos estudos realizados nas respectivas seções, foram identificadas várias doenças das laranjeiras: leprose, verrugose da laranjeira doce, gomose, fuligem, mancha parda, psorose, podridão do pé, etc., classificando e analisando os fitopatógenos: vírus, fungos e bactérias e as formas de transmissão por meio de vetores.

15 Victoria Rossetti foi a primeira engenheira agrônoma formada pela Escola Superior Agrícola Luiz de Queiroz - Esalq, em 1939. Trabalhou de 1941 a 1987 no IB e continuou como pesquisadora aposentada até 2000, quando a doença a retirou da ativa. Dedicou 55 anos ao IB, sendo, por 20 anos, chefe da Patologia Vegetal. Faleceu aos 93 anos, no dia 26 de dezembro de 2010, em São Paulo. 
O conhecimento sistematizado das pesquisas levou Agesilau A. Bitancourt, José Pinto da Fonseca, Mário Autuori e Edmundo Navarro de Andrade a publicarem, em 1933, o livro Manual de Citricultura, que, segundo as palavras de Sylvio Moreira (1991, p. 10), tornou-se "a bíblia dos técnicos e dos citricultores brasileiros", sendo consultada até nos anos 1980 .

Um acontecimento significativo ocorreu em 1934, quando Bitancourt identificou a presença da bactéria Xanthomonas campestris pv. citri, causadora do cancro cítrico, em mudas de laranja importadas do Japão. Foram destruídas, queimadas, para evitar a entrada de uma das mais temidas moléstias de citros. Infelizmente, em 1957, a ameaça tornou-se realidade, quando Bitancourt a identificou em pomares da regiāo de Sorocaba (RIBEIRO, 2007).

Nos estudos das doenças das plantas cítricas, consolidou-se uma das colaboraçôes mais constantes entre Brasil e Estados Unidos, entre o IB e o Departamento de Agricultura dos Estados Unidos, provavelmente por um claro interesse do governo norte-americano em promover o intercâmbio de informações e, também, pelo reconhecimento das contribuições dos institutos públicos de pesquisa à citricultura brasileira. A parceria estendeu-se à Estação Experimental de Citricultura de Riverside, pertencente à Universidade da Califórnia.

Em 1942, surgiu um novo problema: uma doença desconhecida atacava os laranjais paulistas - a tristeza. Coube a Agesilau A. Bitancourt coordenar a Comissão de Estudos da Tristeza, ${ }^{16}$ formada pela Secretaria da Agricultura para realizar um levantamento fitossanitário, estudar a etiologia da doença e realizar experimentos de porta-enxertos (cavalo). Foram quatro anos de trabalho, com resultados exitosos: os pesquisadores identificaram a causa (vírus); determinaram a forma de desenvolvimento da moléstia na planta (porta-enxerto), assim como o vetor de propagação (pulgão preto dos laranjais); elaboraram medidas de controle - substituição das plantas enxertadas em laranja azeda por limoeiro cravo. Entretanto, foi necessário queimar mais de 10 milhóes de árvores. A recuperação dos pomares levou mais de dez anos. A produção de laranjas, que era de 518 mil toneladas em 1942, foi reduzida para 98 mil em 1952. Somente em 1959 ultrapassou a de 1942, chegando a 590 mil toneladas (RAMOS, 1999, p. 28, 30 e 31). 
Depois do inverno norte-americano de 1962-1963, quando a geada destruiu 16 milhões de pés de laranja na Flórida, a citricultura brasileira transformou-se completamente. $\mathrm{O}$ suco de laranja tornou-se o principal produto de comercialização no mercado internacional, superando a exportação de laranja in natura.

A rápida expansão da cultura, impulsionada pela industrialização da laranja e pela exportação do suco (SLCC), trouxe consigo também a disseminação de problemas fitossanitários. Uma das doenças mais temidas, o cancro cítrico, ${ }^{17}$ iniciou sua insidiosa penetração nos pomares. Para evitar sua propagação para a região exportadora de laranja, o IB desencadeou a maior campanha fitossanitária jamais vista no Brasil, segundo Bitancourt, superior até mesmo à empreendida contra a broca do café. A razão era que cancro cítrico constava dos regulamentos fitossanitários internacionais, portanto, autorizava os países a proibirem a importação oriunda de regiōes contaminadas, por motivo de proteção sanitária (RIBEIRO, 1997, p. 174).

Nos estudos da fitopatologia dos citros, Victoria Rossetti passou vários anos dedicados ao fungo do gênero Phytophthora, causador da gomose. Participou da campanha contra a tristeza, analisando porta-enxertos tolerantes a ambas (ROSSETTI, 1995, p. 407). Estudou a exocorte, lesão encontrada originalmente no porta-enxerto do limoeiro-cravo, em diversas variedades de frutas cítricas. Envolveu-se com estudos da leprose dos citros, um problema grave, comprovando a participação do ácaro Brevipalpus phoenicis na propagação da doença, como Bitancourt havia demonstrado pela primeira vez em 1940.

Nos anos 1970, Victoria coordenou os trabalhos para estabelecer os primeiros parâmetros da doença denominada por declínio. Ainda hoje, sua causa continua uma incógnita. Para seu controle, tem sido feita a substituição das árvores que definham.

Em 1987, com o surgimento da Clorose Variegada dos Citros - CVC, Victoria, já aposentada pela compulsória, entretanto mantendo-se mais ativa do que nunca, preparou experimentos em pomares da empresa de suco de laranja Sucocítrico Cutrale S. A., em Colina, SP. Formou-se o Grupo de Trabalho sobre CVC, envolvendo uma rede de instituições e de pesquisadores oriundos do IAC, Jorgino Pompeu Junior e José Antonio Quaggio, da Cutrale, o técnico Mauro Pereira Gomes e o engenheiro agrônomo Luiz Ventura de Aquino, do Cati, José Dagoberto de Negri, da Fundecitrus e do próprio IB, Maria Julia Gobbo Beretta, Maria Ligia anos antes nos Estados Unidos, na Austrália, na Nova Zelândia, na África do Sul e em Moçambique, tendo sido erradicado graças a uma intensa campanha nesses países. É provável que tenha chegado a São Paulo por meio de sementes ou mudas de plantas cítricas trazidas clandestinamente do Japão. 
Veiga Carvalho, Cezar Martins Chagas e Ana Regina Rocha Teixeira (ROSSETTI, 1995, p. 411). Diariamente, os experimentos eram observados para acompanhar sua evolução, a forma de transmissão, a resistência varietal à doença e o agente causal. Segundo Eduardo Feichtenberger, Victoria estava temerosa de que a doença, até então desconhecida, fosse o terrível greening, que ainda não chegara ao Brasil. ${ }^{18}$ Para se certificar da natureza da doença, enviava material dos experimentos, por correio, para seus colegas Joseph Marie Bove e Monique Garnier, do Inra, que, por meio da microscopia eletrônica, buscavam localizar bactérias no floema ou no xilema ${ }^{19}$ e identificá-las. $=$

Dessa colaboração frutífera entre IB, IAC, Cati, Cutrale, Fundecitrus e Inra, resultou a descoberta do agente causal, a bactéria Xylella fastidiosa. Nos laboratórios do Inra, a Dra. Monique Garnier observou sua presença no xilema das laranjeiras, descartando a hipótese de greening.

Nos primeiros dias de janeiro de 1990, por telefone, Dra. Garnier comunicou a Victoria o achado e enviou as fotos em microscopia eletrônica. Imediatamente, Vitoria convocou reunião do Grupo de Trabalho sobre CVC, nos dia 4 e 5 de janeiro, em Araraquara, para comunicar oficialmente a descoberta. ${ }^{20}$

O primeiro trabalho, contendo a descrição da doença, em idioma estrangeiro, e a descoberta da bactéria, tendo como primeira autora Victoria Rossetti, é um marco histórico e, por isso, incluímos nessa Memória. Seguiu-se a comprovação por meio de novos ensaios, confirmando os postulados do ciclo de Koch (ROSSETTI, 1995, p. 412). Em 1993, Victoria constatou a participação de um vetor aéreo na transmissão da doença, as cigarrinhas da Família Cicadellidae, consolidando as bases para o controle da doença.

Em setembro de 1997, a Fapesp aprovou o projeto de sequenciar o DNA de genes de uma bactéria. A escolha do primeiro sequenciamento do DNA recaiu sobre a Xylella fastidiosa. Com isso, o Brasil tornou-se o primeiro país do mundo a ter um fitopatógeno de citros com código genético decifrado.

18 Agradeço a colaboração e gentileza de Eduardo Feichtenberger, pesquisador cientifico da Unidade de Pesquisa e Desenvolvimento "Dra. Victoria Rossetti" , da Agência Paulista de Tecnologia dos Agronegócios - Apta, Sorocaba, por me relatar esta suposição de Victoria quanto à natureza do CVC, pelas referências bibliográficas e pelo envio do artigo e do resumo.

19 Em Botânica, o floema é o tecido das plantas vasculares encarregado de levar a seiva, elaborada pelo caule, até a raiz e aos órgãos de reserva. Xilema é o tecido das plantas vasculares por onde circula a água com sais minerais dissolvidos - seiva bruta - desde a raiz até as folhas. Disponível em: <http://pt.wikipedia.org/wiki/>. Acesso em: 2 abr. 2011.

20 Infelizmente, não consegui localizar esse documento - Ata da Reunião do Grupo de Trabalho sobre CVC, Araraquara, 4 e 5 de janeiro de 1990. Agradeço ao Dr. Jorgino Pompeu Júnior, do IAC, e ao Dr. Antonio Juliano Ayres, da Fundecitrus, pela gentileza em me ajudar. 


\section{Referências bibliográficas}

MARTINS, Zoraide. Agricultura paulista. Uma história maior que cem anos. São Paulo: Secretaria da Agricultura e Abastecimento, 1991.

MEIO \& PESQUISA, São Paulo, v. 2, n. 13, abril de 1997.

MOREIRA, Sylvio. A história da citricultura no Brasil. In: RODRIGUEZ, O.; VIÉGAS, F. Citricultura brasileira. 2a . ed., Campinas, Fundação Cargill, v.1, 1991, p. 3-28.

NEIVA, Arthur. Os trabalhos da comissão de estudo e debelação da praga cafeeira, desde seu inicio. Relatório apresentado ao Snr. Dr. Fernando Costa, Secretário da Agricultura, Indústria e Comércio. São Paulo: Comissão de Estudos e Debelação da Praga Cafeeira, 1928. (Publicação n. 21).

RAMOS FIILHO, Luiz Octávio. O papel da pesquisa cientifica e tecnológica no desenvolvimento da citricultura paulista: análise histórica da atuação do Instituto Agronômico de Campinas 1920-1960. Dissertação (Mestrado em Política Científica e Tecnológica). Campinas: Instituto de Geociências, Universidade Estadual de Campinas, 1999.

REIS, José. O Instituto Biológico e assistência aos lavradores e criadores. Excursão a Quatá. (Colônia Evangelista de Palma). O Biológico, São Paulo, v. 5, n. 7, p. 129-32, 1939.

. Começos da pesquisa veterinária no Instituto Biológico. Ciência e Cultura, São Paulo, v. 35, n. 7, p. 988-92, 1983.

abril 1976 .

. Rocha Lima, o homem e a obra. Ciência e Cultura, São Paulo, v. 28, n. 4,

REIS, José; NÓBREGA, Paulo; REIS, Anita S. Tratado de doenças das aves. São Paulo: Instituto Biológico, 1936.

RIBEIRO, Maria Alice Rosa. História sem fim... inventário da saúde pública. São Paulo: Editora Unesp, 1993.

História, Ciência e Tecnologia - 70 anos do Instituto Biológico de São Paulo na defesa da agricultura 1927-1997. São Paulo: Instituto Biológico, 1997.

- Uma instituição pública de pesquisa científica e tecnológica em um mundo em transformação: Instituto Biológico de São Paulo 1998-2010. São Paulo: Instituto Biológico, 2010.

Desenvolvimento da citricultura brasileira e a pesquisa científica e tecnológica (1930-2006). I Congreso Latinoamericano de Historia Econômica. CLADHE I. Simpósio 31 - Ciência, Tecnologia e História Econômica, 5 a 7 de dezembro de 2007, em Montevidéu. (Coordenadores Tamás Szmrecsányi e Luiz Carlos Soares). 
ROCHA E SILVA, Maurício. Necrológico. Henrique da Rocha Lima. Revista Brasileira de Medicina, Rio de Janeiro, v. 13, n. 6, junho 1956.

ROSSETTI, Victoria. Agesilau Antonio Bitancourt. Fitopatologia brasileira. Revista Oficial da Sociedade Brasileira de Fitopatologia, v. 12, n. 3, p. 290-2, setembro 1987. Autobiografia. Revista Anual de Patologia de Plantas. RAPP, v. 3, p. 391- 429, 1995.

ROSSETTI, Victoria; GARNIER, Monique; BOVE, Joseph Marie; BERETTA, Maria Julia Gobbo; TEIXEIRA, Ana Regina Rocha; QUAGGIO, José Antonio; NEGRI, José Dagoberto de. Présence de bacteries dans le xylème d'orangers atteinst de chlorose variégée, une nouvelle maladie des agrumes au Brésil. Comptes Rendus Academie Science Paris, t. 10, Série III, p. 345-349, 1990.

RUBIN, Luciane da Silva; OLIVEIRA, Suellen M.; SILVA, Tania Nunes da. Distorções no mercado Internacional de frangos e as exportações de carne de frango. Informaçôes Econômicas, São Paulo, v. 39, n. 11, nov. 2009. Disponível em: <http://www.iea.sp.gov.br>. Acesso em: 20 set. 2010. 

Pathologie végétale/Plant Pathology

\section{Présence de bactéries dans le xylème d'orangers atteints de chlorose variégée, une nouvelle maladie des agrumes au Brésil}

Victoria Rossetri, Monique Garnier, Joseph Marie Bove, Maria-Julia-Gobbo Beretta, Ana Regina Rocha Teixeira, José Antonio Quaggio et Jose Dagoberto DE NEGRI

Résumé - Une nouvelle maladie des agrumes, la chlorose variégée, est apparue au Brésil en 1987. Cette maladie se répand rapidement suggerant une transmission par insecte vecteur. Nous reportons ici la mise en évidence de bactéries dans le xylème des orangers affectés.

Occurrence of xylem-restricted bacteria in sweet orange trees affected by chlorotic variegation, a new citrus disease in Brazil

Abstract - A new disease of citrus, chlorotic variegation, appeared in 1987 in Brazil. The rapid spread of this disease suggests insect transmission. We report here the presence of bacteria in the xylem of affected sweet orange trees.

Abridged English Version - Introduction. - Since June 1987, abnormal citrus trees have been detected in an orchard of the southwestern part of the State of Minas Gerais, Brazil. The same symptoms have also been observed in the following areas of the northern part of the neighbouring State of São Paulo: Macaubal, where the affection is extremely severe, Colina, Jaborandi and others.

REsults. - Symptoms and affected varieties. - The leaves of new sprouts show chlorosis patterns similar to those of zinc deficiency symptoms; on older leaves, a conspicuous variegation is observed. On the lower side, leaves show small, light-brown lesions corresponding to the yellow chlorotic areas seen on the upper side; these areas may become dark-brown or necrotic. The lesions are punctiform or elongated, somewhat raised, and occur in clusters or sometimes in lines. The fruits are very small and hardened; production is greatly reduced. Nothing abnormal has been observed on the roots. Natal, Pera, Hamlin, Selecta and Valencia sweet orange varieties grafted on Rangpur lime, Clocpatra mandarin, or C. volkameriana rootstocks have been found to be affected. Tahiti lime and madarin trees do not show symptoms even when planted, in severely affected orchards, close to diseased sweet orange trees. Trees start showing symptoms when they are 3 to 5 years old and the disease spreads quickly. In a Colina orchard with 2.000 trees 2 affected trees were found in 1987,16 in 1988 and about 300 in 1989.

Mineral analysis indicates that, in affected trees, the levels of nitrogen, phosphorus, zinc and potassium are reduced while those of calcium and boron are increased.

Observation of phloem and xylem from infected leaves and fruits by electron microscopy. Leaf midribs and fruit axes from healthy and infected trees from Macaubal, Colina and Jaborandi were observed by electron microscopy. Filamentous bacteria ( 1 to $4 \mu \mathrm{m}$ long, 0.25 to $0.5 \mu \mathrm{m}$ in diameter) were found in the xylem of all infected samples ( Fig.) but not in the xylem of the samples from symptomless trees in the same orchards. The bacteria are very numerous in some vessels of fruit axes (Fig. B-E) as well as of leaf midribs

Note présentée par Henri DuRanTon.

0764-4469/90/03100345 \$2.00@ Académie des Sciences 
(Fig. A). They are sometimes embedded in an electron-luscent matrix (Fig. D-E). They are of the Gram negative type with sometimes a rippled wall (Fig. C).

Discussion. - Our results show that chlorotic variegation of sweet orange trees in Brazil is correlated with the presence of bacteria in the xylem. These bacteria are not found in healthy trees. Their morphology is similar to that described for the bacterium causing Pierce's disease in grapevines ([1], [2]). Similar bacteria have also been found in many other plant species. They correspond to various strains of Xylella fastidiosa [3] which is transmitted by sharpshooter ([3], [4]). Whether the bacterium associated with chlorotic variegation belongs to this same groupe of bacteria, remains to be determined. The rapid spreading of the disease also suggests the presence of an insect vector. As high populations of sharpshooters have been found in Brazil [6], their role in the epidemiology of the disease is under investigation.

InTRODuction. - En juin 1987 nous avons observé des symptômes inhabituels dans des vergers d'orangers du Sud-Ouest de l'État de Minas Gerais. Les mêmes symptômes ont ensuite été observés dans de nombreux vergers dés régions limitrophes de l'État de Sao Paulo, et plus particulièrement à Colina, Jaborandi et surtout Macaubal où la maladie est très sévère. Nous venons maintenant de mettre en évidence pour la première fois des bactéries dans le xylème des nervures foliaires des columelles de fruits provenant d'arbres malades.

RÉsultats. - Symptômes et variétés affectées. - Les symptômes apparaissent sur les orangers âgés de 3 à 5 ans. Les feuilles des nouvelles pousses montrent un type de chlorose ressemblant à des symptômes de carence en zinc. Sur la face supérieure des feuilles âgées, la chlorose se traduit par une variégation accentuée, caractérisée par des taches jaunes irrégulières, parfois nécrotiques, entre les nervures secondaires. Sur la face inférieure et correspondant aux taches jaunes, on remarque la présence de nombreuses lésions brunes d'environ 1 à $2 \mathrm{~mm}$ de long, plus ou moins nécrotiques. Elles sont légèrement surélevées par rapport à la surface de la feuille. Elles sont isolées ou associées à plusieurs, parfois disposées en une ligne parallèle à la nervure secondaire.

Les fruits des arbres malades sont très petits par rapport à ceux des arbres normaux et ils ont une consistance dure au toucher. $\mathrm{La}$ production des vergers atteints est très sérieusement diminuée.

Les agrumes qui ont montré les symptômes précédents sont les orangers (Citrus sinensis Osb.) des variétés suivantes: Hamlin, Natal, Pera, Selecta et Valencia; les arbres malades

LÉGENDE DE LA FIGURE

Coupes dans le xylème de nervures médianes de feuilles et de columelles de fruits d'orangers atteints de chlorose variégée (Macaubal). A : Coupe longitudinale dans le xylème d'une nervure de feuille. B, C, D, E : Coupes transversales dans le xylème de columelle de fruit montrant les bactéries libres $(\mathrm{B}, \mathrm{C})$ ou incluses dans une matrice $(D, E)$. Barre $=1 \mu \mathrm{m}$

Electron micrographs of xylem tissue from leaf midribs and fruit axis from sweet orange trees affected by chlorotic variegation (Macaubal). A: Longitudinal section through the xylem of a leaf midrib. $B, C, D, E$ : Cross sections through the xylem of a fruit axis showing free bacteria $(B, C)$ and bacteria embedded in an electronluscent matrix $(D, E)$. Bar $=1 \mu \mathrm{m}$. 


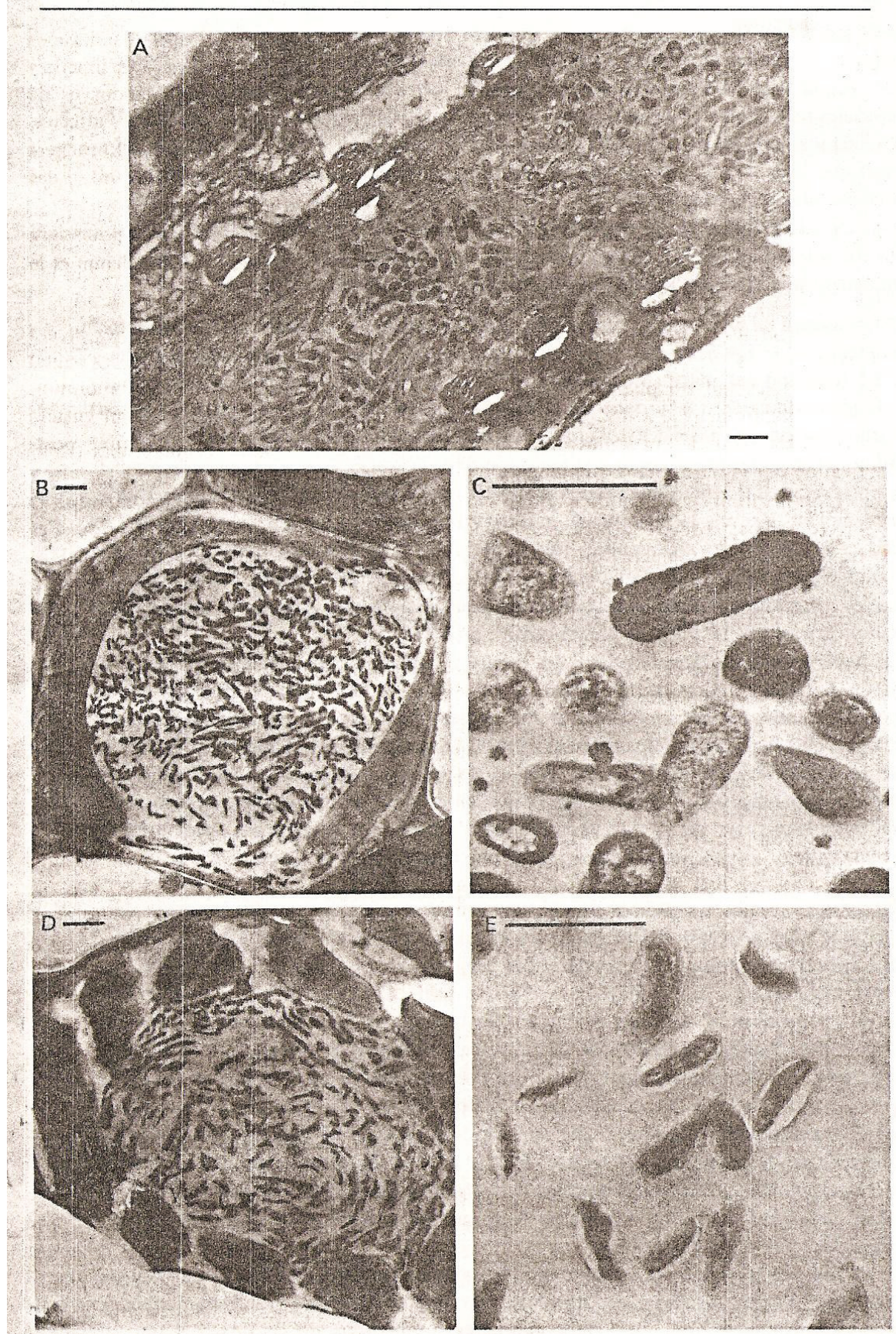


étaient greffés sur les porte-greffes suivants : lime rangpur (C. limonia Osb.), mandarinier Cleopatra (C. reshni Hort. Ex. Tan.) et C. volkameriana Ten. and Pasq. Les limetiers Tahiti (C. latifolia Tan.) et les mandariniers (C. reticulata Blanco) sont dépourvus de symptômes même lorsqu'ils sont voisins d'orangers malades dans des vergers très affectés.

La maladie semble se propager rapidement. A Colina, un verger de 2000 orangers n'avait que deux arbres atteints en 1987 et 16 en 1988 alors qu'en 1989 le nombre des arbres malades atteignait 300 .

L'analyse minérale a révélé que la teneur des feuilles en azote, phosphore, potassium et zinc diminuait lorsque l'intensité des symptômes augmentait alors que le calcium et le bore étaient présents en quantité plus grande dans les feuilles atteintes.

Observations au microscope électronique du phloème et du xylème des feuilles et des fruits malades. - Les échantillons (nervures principales de feuilles et columelle des fruits) ont été fixés soit sur place (Macaubal) soit à Bordeaux (Macaubal, Colina, Jaborandi) par le glutaraldéhyde à $4 \%$ dans du tampon cacodylate $0,1 \mathrm{M}$ pH 7,4. Ils ont ensuite été traités selon les procédés classiques de microscopie électronique après une postfixation par le tétroxyde d'osmium et inclusion dans l'épon 812 .

L'observation des échantillons prélevés sur des arbres présentant les symptômes décrits précédemment, a révélé la présence de bactéries dans les vaisseaux du xylème (fig.). Ces bactéries sont présentes en quantités très importantes dans certains vaisseaux tant dans les columelles des fruits ( $f i g$. B-E) que dans les nervures principales des feuilles ( fig. A). D'autres vaisseaux adjacents contiennent des bactéries en quantités moins importantes. Aucun microorganisme n'a été observé dans le phloème.

* La bactérie observée dans le xylème des orangers atteints, est filamenteuse. Sa longueur varie de 1 à $4 \mu \mathrm{m}$ et son diamètre de 0,25 à $0,5 \mu \mathrm{m}$. Son enveloppe est de type Gram négatif, la membrane externe étant souvent ondulée ( fig. C). Certaines bactéries ont une enveloppe plus dense dans laquelle il est difficile de distinguer les membranes internes et externes. Dans certains vaisseaux du xylème, les bactéries semblent incluses dans une matrice transparente aux électrons ( fig. D, E); elles ont alors une morphologie allongée et un cytoplasme très dense. Les échantillons d'arbres sans symptômes, mais prélevés dans des vergers atteints, ne renfermaient aucune bactérie dans le xylème.

Discussion. - Les symptômes de chlorose variégée, observés sur des orangers dans les états de Minas Gerais et Sao Paulo au Brésil, ont pu être corrélés avec la présence de bactéries dans le xylème. Ces bactéries ont toujours été observées dans les échantillons d'arbres malades mais jamais dans ceux d'arbres sains. Les deux aspects de la bactérie, celui où les membranes externes et internes de l'enveloppe sont bien individualisées et celui où, on les distingue difficilement, et qui correspondraient à divers stades de multiplication, sont en tout point comparables à ceux décrits pour la bactérie présente dans le xylème de vigne atteinte par la maladie de Pierce ([1], [2]). Il en est de même pour la présence dans certains vaisseaux d'une matrice dans laquelle les bactéries sont incluses. Le même type de bactérie a été trouvé dans le xylème de nombreuses autres plantes. Elles correspondent à différentes souches de Xylella fastidiosa [3]. L'appartenance de la bactérie associée à la chlorose variégée à ce groupe d'agent pathogène reste à être confirmée.

La progression rapide de la maladie semble indiquer la présence d'un insecte vecteur. On sait que Xylella fastidiosa est transmise par des cicadelles se nourrissant dans le xylème (sharpshooters) ([3], [4]). De nombreuses populations de ces insectes ont été 
BLIOGRAPHIQUES

ins et H. H. Mollenhauer, Science, 179, 1973, p. 298-300.

-ENHAUER et D. L. Hopkins, J. Bacteriol., 119, 1974, p. 612-618.

INS, Annu. Review Phytopathol., 27, 1989, p. 271-290.

ELL, in Leafhopper vectors and plant disease agents, K. MARAmOROSCH et K. F. Harris éd.,

ifevre, M. J. G. Beretta, V. Rossetti, R. H. Brlansky et R. F. Lee, in L. W. Timmer, L. Navarro éd., $10^{e}$ Conférence de l'Organization Internationale des Virologistes des Agrumes 388-392.

V. R., M. J. G. B et A. R. R. : Instituto Biologico, C.P. 7119, Sao Paulo, Brazil, M. G. et J. M. B. : Institut national de la Recherche agronomique (I.N.R.A.), Laboratoire de Biologie cellulaire et moléculaire, B.P. n' 81, 33883 Villenave-d'Ornon Cedex;

J. A. Q. : Instituto Agronomico, C.P. 28, Campinas-SP, Brazil; J. D. de N. : C.A.T.I., C.P. 960, Campinas-SP, Brazil. 


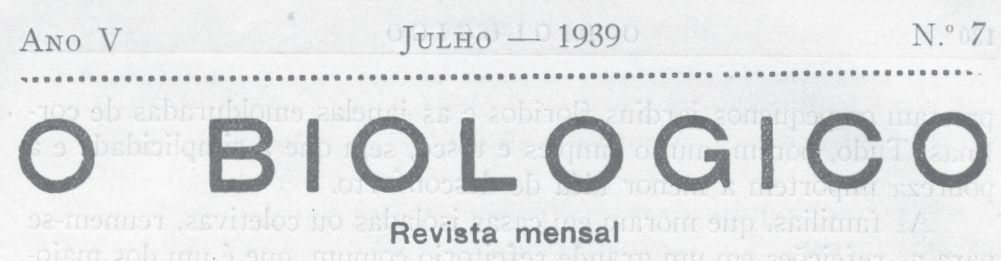

\title{
O Instifuito Biologico e a assis- tencia aos lavradores e criadores
}

\author{
Excursão a Quatá \\ (Colonia Evangelista de Palma)
}

\section{J. Reis}

Existem nas imediações de Quatá (E. F. S.) diversos agrupamentos humanos muito curiosos, formados especialmente de japoneses e letões. Um deles, a Colonia Evangelica de Palma, é constituido por operosos letões que ha uns doze anos se fixaram em plena mata, creando uma comunidade agricola que aos poucos foi crescendo.

A terra não é das melhores, mas ainda assim tem recompenado com messes alviçareiras a esperança dos colonos que, derrubada a mata, se lançaram ao trabalho das primeiras sementeiras.

O leite, o mel e os ovos, assim como alguns cereais comuns, são lá mesmo obtidos. A população diferenciou-se de acordo com os diversos misteres que as necessidades gerais impõem: a maioria dedica-se ao tratu da terra e das criações, enquanto outros zelam pelas maquinas e teares e improvisam aparelhos e peças mecanicas.

L.eva a colonia uma existência quasi "autarquica", pois, além de produzir e fabricar o principal do que seus habitantes necessitam, ainda possue tipografia, fotografo, jornal etc. E' provida de luz eletrica gerada em usina propria, instalada pelos seus proprios habitantes. Grande numero de maquinas usadas para o beneficiamento dos produtos agrícolas é feito de madeira. Chocadeiras. de excelente acabamento, são lá mesmo fabricadas em todos os detalhes, assim como criadeiras e objetos diversos para a avicultura.

Todas as casas, exceto a igreja, são de madeira, curiosas pelo bom gosto da construção e pelo aspecto alegre e prospero que thes em- 
prestam os pequenos jardins floridos e as janelas emolduradas de cortinas. Tudo, porém, muito simples e tosco, sem que a simplicidade e a pobrezá importem a menor idéa de desconforto.

As familias, que moram em casas isoladas ou coletivas, reunem-se para as refeiçóes em um grande refeitorio comum, que é um dos maiores edificios da colonia. Interessante assinalar o asseio impressionante de todos os comodos e utensilios.

Para chegar a Palma, o viajante, saltando na estação de Quatá, serve-se de jardineira até Varpa (outro centro letão) e daí prossegue a cavalo. O caminho de automovel, aberto em terreno arenoso, é de difícil transito, obrigando o veículo a seguir dentro de trilhos fundos, dos quais é dificil sair, de sorte que o encontro de dois veículos em direçôes vpostas obriga os motoristas a manobras complicadas. Não obstante esse incoveniente, não é pequeno o movimento da estrada, sobretudo trilhada por caminhões.

Nos declives mais acentuados e nos pontos de mais dificil passagem, a estrada é "calçada" com taboas, formando longos e largos trilhos concavos.

$$
* * *
$$

Atualmente, o grosso das atividades da colonia concentra-se na criação de galinhas, cujos ovos são enviados em grande quantidade a Săo Paulo, assim como na produção de farinha fina de mandioca para atender às necessiddes do fabrico do "pão mixto".

Só a comunidade de Palma possue cerca de 3000 cabeças de Leghorns. Nas vizinhanças da colonia e em nucleos proximos, de japoneses e letões, tambem é intensa a criação de galinhas, em geral bem orientada. E' sobremodo agradavel deparar, no meio do mato, tais criações modernas, de aves tão refinadas.

$$
* * *
$$

Ha tempos vem o Instituto Biologico prestando assistencia técnica a essa corporação de Palma no que se refere ao combate das molestias de animais e plantas.

Esta colaboração começou por intermedio da Seção de Ornitopatologia, cujos técnicos lá chegaram, como têm feito a muitos outros pentos longinquos do Estado, com o intuito de proteger e fomentar com sua assistencia essa grande fonte de riquesa que é a avicultura.

Estabelecidos os primeiros contactos, e verificada pelos colonos a excelencia do auxilio que thes presta o Governo por intermedio do Instituto, era natural que procurassem cada vez mais aproximar-se deste utimo, apresentando-the novos problemas, que têm sido sempre resolvidos a contento, e confiando a êle a supervisão técnica de suas criações e culturas.

Como consequencia natural dessa aproximação cada vez mais estreita, já estiveram em Palma técnicos da Seção de Entomologia Agrí- 
cola, estudando e combatendo pragas dos mandiocais, e, mais recentemente um técnico do serviço de Assistencia Veterinaria estudando as molestias do gado.

Estas visitas foram todas feitas em conjunto com o técnico da Seção de Ornitopatologia, e bem refletem a util harmonia que une os vários departamentos do Instituto Biologico, todos eles trabalhando entusiasticamente por um fim unico, que é servir com presteza e eficiencia os agricultores e criadores do Estado.

A ultima visita feita a Palma constituiu verdadeira caravana de finalidades técnicas, que estamos certos, acarretou enormes beneficios aos agricultores. Era constituicla pelo dr. Mario D'Apice, por nós e pelo Snr. Anadir França, e chegou a Quatá no dia 23 de maio.

O sr. Anadir França logo se entregou aos trabalhos de erradicaçăo dá pulorose por meio do reconhecimento de portadores, serviço que vein sendo realizado paulatinamente em todo o Estado. Tendo-se demorał lo alguns dias nessa localidade, pôde atender não só ao aviario da colonia de: Palma, mas tambem a sitiantes dos arredores.

O dr. Mario D'Apice teve oportunidade de atender a numerosas consulias e examinar varios animais, dispensando preciosos conselhos aos criadores sobre a maneira de lutar contra as principais doenças que ê'e pôde observar na criação, assim como, sobre higiene das criações em geral.

Quanto a nós, limitamo-nos a observar o aviario da colonia, cujas condições de instalação e higiene já nos eram familiares, graças à estreita colaboração que vem sendo mantida entre a Seção de Ornitopatologia e a colonia agrícola.

O aviario é construido de maneira inteligente e de acordo com os pr:icipios da higiene, apesar de ser todo ele de madeira.

Na noite do dia 23 houve uma concentração de agricultores de Palma e nucleos vizinhos no grande salão do refeitorio. A pequena colonia adquuiriu então movimento desusado. Desde o crepusculo começaram a aparecer interessados, cujo numero foi rapidamente aumentando. Até onibus especial lá apareceu, carregado de lavradores. Calculamos em perto de cem o numero das pessôas que se reuniram no refeitorio, onde c dr. D'Apice e nós tivemos oportunidade de falar sôbre as principais molestias de aves e outros animais.

As preleções realizadas despertaram grande interesse entre os criadores, que, depois, fizeram numerosas perguntas, procurando resolver suas duvidas. E' justo salientar o ambiente de cordialidade e disciplina e:n que se efetuou a reunião, na qual os colonos de Palma e arredores demonstraram amplamente suas qualidades inestimaveis de ordem e inteligência.

$$
* * \%
$$

Essa excursão à colonia de Palma sugere algumas reflexões. Em primeiro lugar, demonstra a eficiencia da entrosagem dos serviços do 
Instituto que varios deles já foram mobilizados com toda a presteza e eliciencia para atender às dificuldades dos criadores e agricultores daquele lugar, isso sem a menor dificuldade administrativa ou burocratica, mas como consequencia simples do bom entendimento entre os técn1cos das diversas seções. Não ha de fato no I. Biologico serviços disso ou daquilo, separados por muralhas chinesas ou preconceitos de classe, mas sim técnicos especializados, a se ajudarem mutuamente em beneficio do país. O Instituto é uma unidade e não um agregado de seções.

Segundo, ilustra um dos aspectos mais curiosos da função educativa do Instituto: o de difundir até os mais afastados rincões do Estado conhecimentos técnicos e cientificos e promover contacto muito intimo er:1re os homens de laboratorio e os do campo, familiarizando uns com outros e desfazendo eventuais incompreensões.

Terceiro, é a ação nacionalizante do Instituto. Organização criada e mantida pelo Estado, dirigida e orientada por brasileiro e por brasileiro: servida, o trabalho de seus técnicos e a eficacia do auxilio que êles prestam, faz com que dêle se aproximem, além dos nacionais, os agricultores estrangeiros que entre nós se radicaram formando nucleos mais ou menos extensos, e que asim espontaneamente se colocam dentre da "zona de influencia do Instituto", com o qual colaboram valicsamente. Ora, que thes dá o Instituto? Assistencia eficiente, modelar, como não teriam melhor em seus países de origem, impondo, pelo prestigio de sua eficiencia, o respeito espontaneo ao país que assim se acha organizado e ao Governo que zela por tal estrutura, e continuamente a aperfeiçôa. 


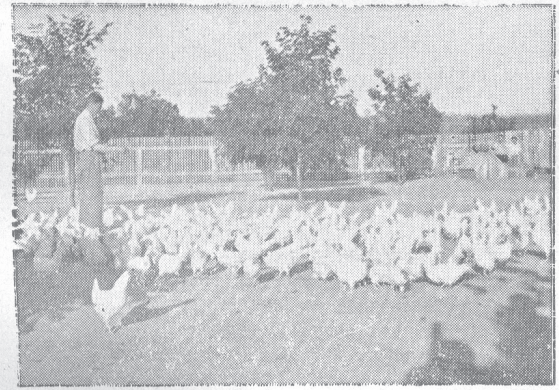

Fig. 1

Parte da criacão de Leghorns de um dos galinheiros da Colonia de Palma. Muito tem traba thado o I. Biologico para ajudar os criadores a manter criações assim, economicas e sadias, em todo o Estado.

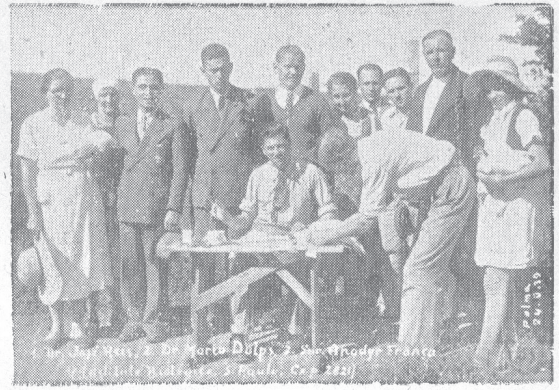

Fig. 2

Pesquisa de portadores de pulorose, pelo metodo de aglutinação rapida (antigeno colorido). V'ê-se o pessoal do Instituto e alguns colonos.

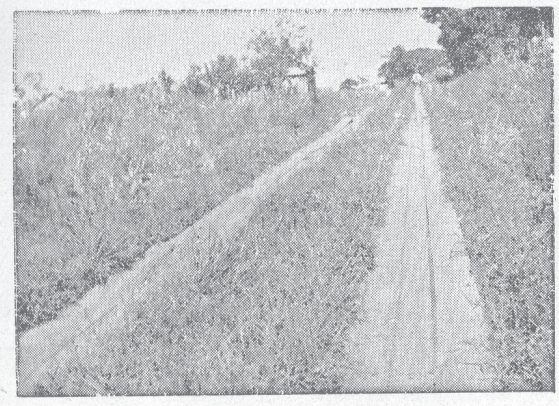

Fig. 3

Trilhos de madeira, na estrada de Quatá a Palma.

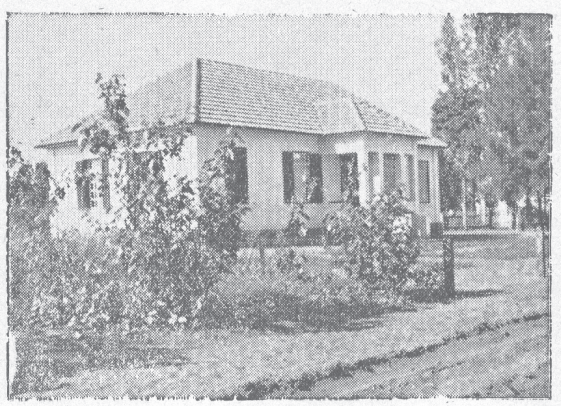

Fig. 4

Hospital de Varpa. 
Os trabalhos submetidos á Revista Brasileira de Inovação (RBI) deve enquadra-se na linha editorial da revista e observar as normas e orientações indicadas abaixo. Serão avaliados no sistema Doubleblind review por pelo menos dois pareceristas, ambos de instituições distintas daquela à qual o(s) autor (es) está(ão) vinculado(s). Os direitos autorais dos trabalhos aprovados são automaticamente transferidos à RBI como condição para sua publicação.

1. A RBI publica artigos e resenhas, assim como reedita trabalhos clássicos e documentos históricos relacionados à temática da revista. Os artigos e resenhas devem ser inéditos e não podem ser simultaneamente submetidos a outra(s) revista(s).

2. Podem ser submetidos trabalhos redigidos em português, inglês ou espanhol.

3. Os originais devem ser submetidos ao editor por e-mail para o seguinte endereço: revistabrasileiradeinovacao@gmail.com acompanhados de um documento submetendo o trabalho para publicação, contendo informações completas sobre o(s) autor(es)> nome, vínculo institucional, endereço para correspondência, telefone, fax e correio eletrônico.

4. Os trabalhos dever ser digitados no editor de texto Word 6.0 ou posterior; fonte Times Roman, corpo 12; margens direita, superior e inferior, $2,5 \mathrm{~cm}$, esquerda $3 \mathrm{~cm}$; espaçamento entrelinhas, 1,5; e alinhamento justificado. Os artigos não devem ultrapassar 10.000 palavras e as resenhas não devem exceder 2.500 palavras.

5. Os artigos devem ser submetidos contendo resumo em português e Abstract em inglês, com no máximo 150 palavras cada; até cinco palavras-chave, também em português e em inglês, e classificação do artigo segundo o Classification System for Journal Articles do Journal of Economic Literature.

6. As referências ou citações devem ser abreviadas no corpo do texto e em notas de pé de página (autor, ano da publicação e , quando for o caso, página), e completas nas referências no final do texto, segundo as normas para apresentação de trabalhos técnico-científicos da ABNT Associação Brasileira de Normas Técnicas. 
